\title{
Nano Technology- The Mini Giant to Ordain the World Soon
}

\author{
Koyel Ghosh* \\ Allied Market Research, 5933 NE Win Silver Dr, Portland, OR 97220, USA
}

\section{Article Info \\ *Corresponding author: Koyel Ghosh \\ Allied Market Research \\ 5933 NE Win Silver Dr, Portland \\ OR 97220, USA \\ E-mail: shaun.godinho@ \\ alliedmarketresearch.com}

Received: December 19, 2018

Accepted: December 26, 2018

Published: December 31, 2018

Citation: Ghosh K. Nano Technology- The Mini Giant to Ordain the World Soon. Madridge J Nanotechnol Nanosci. 2018; 3(2): 119-120.

doi: $10.18689 / \mathrm{mjnn}-1000123$

Copyright: @ 2018 The Author(s). This work is licensed under a Creative Commons Attribution 4.0 International License, which permits unrestricted use, distribution, and reproduction in any medium, provided the original work is properly cited.

Published by Madridge Publishers

\begin{abstract}
The nanoscience research over the last two decades has made the technology come up with an array of applications that are meant to serve the society in more than one way. Even a few years back, nanotechnology was only believed to be used in making certain sports accessories. But, the potential of this mini giant has now overawed this limited stricture.
\end{abstract}

Keywords: Nanotechnology; Nanoscience; Nanomaterials; Nanomedicine; Nanofiltartion

\section{Introduction}

The study conducted on this booming market player has it to state that it will soon cover all the important aspects of life and make it yet more vibrant and exciting. By the year 2020, it's expected to be in extensive use and leave a footmark in almost all the prominent industries. Be it the sector of medicine or new computing system, the trends this technology has on board are anticipated to accelerate beyond the bar and make the world yet more engaging to explore through. This post is going to give you a quick brief of quite a few recent trends concerning nanotechnology.

\section{Nanomaterials for Printing Market}

According to several surveys carried out recently, it's revealed that nanomaterials are highly beneficial for printing market and offers a lucrative business in the years to come. Though it's in the nascent stage right now, the days are not so far when nanomaterials would literally rule over the electronics industry. Especially, Europe, North America and Asia Pacific are likely to come up with a concentrated scenario. The nanomaterials utilized in the printing industry are made of conductive materials and it has made them a perfect choice for electronics contraptions. Mostly, silver, gold and copper are the components used for the same. Perhaps, the thriving demand for exclusive electronics products is right behind triggering nanomaterials in the printing market. Providing top-end precision and accuracy, this technology is almost on the verge of making its use permanent in the market. Modifying the end-use applications is probably the prime objective of this giant technology. According to Allied Market Research, nanomaterials market that was estimated to be $\$ 14,741.6$ in 2015 is assumed to hit $\$ 55,016$ million by the year 2022 with a CAGR of $20.7 \%$ [1].

\section{Nanomedicines in the Health Industry}

The therapies and tests currently available in medical clinics are nothing but the upshots of nanotechnology. Right from cancer to certain oracular diseases, a number of ailments are promised to be cured by this new bliss! The sooner a medical condition is diagnosed, the greater is the chance for the cure and as per several experiments done lately, nothing other than nanotechnology can do the job better. Providing better 
bioavailability, nanomedicines have not only revolutionized the entire healthcare industry, but have also broadened the path for improved medical solutions.

\section{The Use of Nanofiltration Membrane is also on the rise}

While dealing with amoxicillin waste water, nanofiltration membrane is proven to be one of the most effective constituents. While it works as an antibiotic to fight against several infections, it also functions as a deterrent to long-term adverse health effects. Again, dairy industry is the one to reap huge benefits from the technology. By helping in the separation of certain components of whey and milk, nanofiltration membrane triggers the dairy processing to a significant extent. Last but not the least; it aids in the retrieval of copper from the acid rinse water, thereby supporting the textile industry as well.

\section{Nanotechnology in Renewable Energy}

Despite being a new emergent in the market, nanotechnology has started citing its promising potential in various domains of science and technology. And, the active role of nanomaterials in improving the efficiency of renewable energy is the major proof against the high-end power of the technology. While nanostructures can produce thin film PV cells, nanoparticles can also make the best use of the relatively cheaper material like silicon and form efficient solar cells. According to different studies done on this giant tech, modern fuel cells come with huge prospects to perk up transportation and the scientists working on this domain have made nanotechnology improve the fuel cell performance to a great extent. Again, when it comes to batteries, the challenge is to find the most suitable material for the electrodes. Here, yet again, nanomaterial works as the best component, as it provides less flammable material and thus, checks the possibility of catching fire. Moreover, the miniscule size of nanowires and nanotubes can help in meeting the demand of small, low-cost sensors used in airports to detect the smell of unwanted vapors.

\section{Conclusion}

Nanotechnology has a long way to pave in. The potency of this giant technology has already been felt by almost all the budding industries and in the coming years, it's quite likely to rule over the market all throughout the world.

\section{References}

1. Nanotechnology world network.2013. 